\title{
OBITUARY
}

\section{EDWARD FFOLLIOTT CREED}

It is with sorrow that we have to record the sudden death of Edward ffolliott Creed at the age of 54 during his convalescence from a severe illness. $\mathrm{He}$ was one of the original members of the Association of Clinical Pathologists. He had succeeded W. D'Este Emery as director to the Pathological Department at King's College Hospital in 1921. There had been several months' delay in filling the post, perhaps because of doubts in the minds of his colleagues due to his relative youth and inexperience. These doubts were soon set at rest and the Department flourished under his care.

Creed was largely responsible for what was, in the early nineteen-twenties, an innovation in teaching hospitals - namely, the creation of a post of resident assistant clinical pathologist. His intention was probably twofold: first, to introduce the budding physician or surgeon to a working knowledge of laboratory methods in clinical medicine, and help him not only to understand clinical medicine the better but also, and perhaps more important, to appreciate the value and limitations of laboratory methods; secondly, to provide the early training ground for the clinical pathologist of the future. This was a very necessary provision, because up till then almost the only way for one who wished to become a clinical pathologist was to enter a university pathological laboratory as a junior demonstrator and go through a training which, though of great value educationally and scientifically, often failed to provide all that was needed for one who would be in charge of a clinical laboratory. The resident pathologist also learnt to bridge the gap between bedside and laboratory, on the one hand helping his colleagues the house physician and house surgeon to use the laboratory more efficiently and less wastefully; and on the other, keeping the laboratory closely in touch with what was going on in the wards. Creed felt strongly the constant need for this close association, and resisted all measures which threatened it, such as the siting of laboratories at distances from the wards. Pari passu he was not attracted by postal pathology,

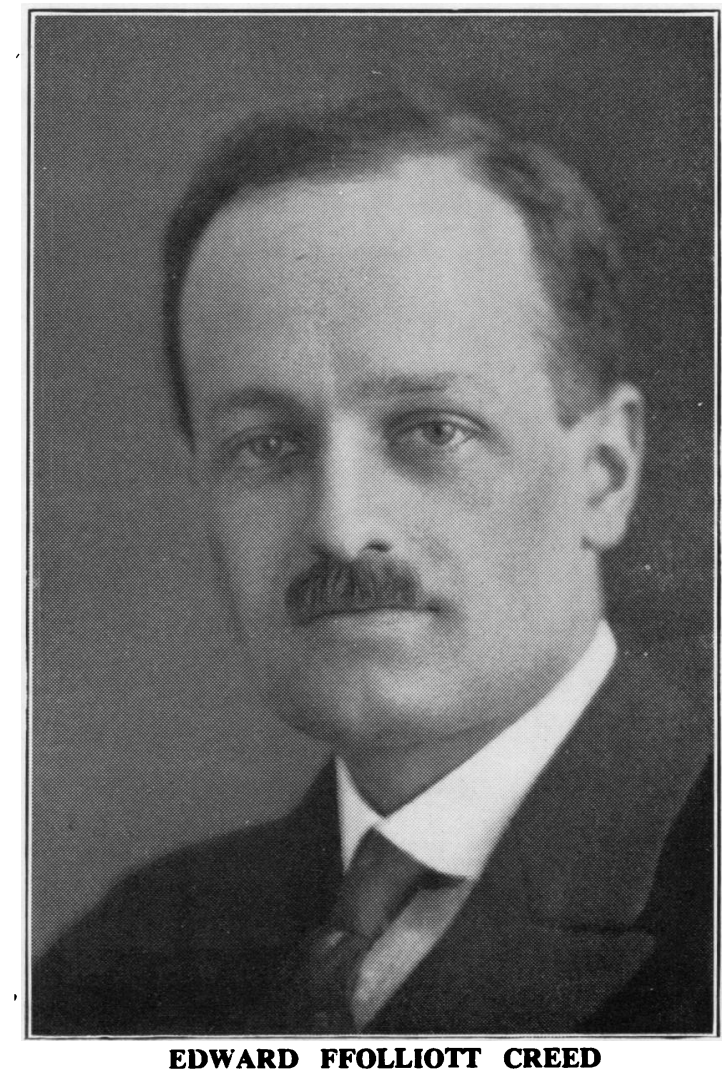

and he tolerated it only because of the exigencies of the time.

H. A. Osborn was the first, Terence East the second holder of the new post. I was the third, and there have since been a succession of trainees who are now scattered over the country, many of them running laboratories; some, practising in other fields, now 
know that their spell in clinical pathology under his guidance was time well spent.

To one closely in touch with him over the last quarter of a century, an outstanding feature in his character was his humility and tolerance, shown even to the callow and the ignorant. He remained free from the accretions of dogma and self-assurance which are apt to clog the minds of teachers in their fifth or sixth decades. His humility was genuine, and prevented him from publishing work which ought to have been published long since-for example, his careful and critical elaboration and assessment of the technique of blood fragility estimation, which he did not publish for some fifteen years. His humility was not due to any lack of critical faculty; he was quick in finding weak spots in an argument. Some of us can recall the quiet way in which after a meeting he could on occasions tear to pieces an elaborate and convincing thesis.

He was a pupil of Georges Dreyer, of Oxford, and was essentially a clinical pathologist. His interest always lay in the practical application of pathology to medicine. He was too occupied in perfecting techniques for routine work to tackle more basic problems. He upheld the tradition that the pathologist of should be constantly at the bedside, and as his interest $\vec{\circ}$ lay in clinical problems his heart was in his work.

A careful and patient teacher to the many, to the few who knew him well his loss will be keener and more personal. They will miss a delightful and sympathetic companion, perhaps a trifle reserved, but one whose conversation, full of wisdom, was lit by frequent shafts of whimsical humour.

C. H. WhitTLE.

We regret to record the death of Professor James McIntosh, Director of the Bland-Sutton Institute of Pathology, Middlesex Hospital, and Professor of Pathology in the University of London. 